University of Nebraska - Lincoln

DigitalCommons@University of Nebraska - Lincoln

Faculty Publications in Food Science and Technology

Food Science and Technology Department

2005

Functionality Behavior of Raw and Extruded Corn Starch Mixtures

Serap Ozcan

University of Nebraska-Lincoln

David S. Jackson

University of Nebraska-Lincoln, djackson1@unl.edu

Follow this and additional works at: https://digitalcommons.unl.edu/foodsciefacpub

Part of the Food Science Commons

Ozcan, Serap and Jackson, David S., "Functionality Behavior of Raw and Extruded Corn Starch Mixtures" (2005). Faculty Publications in Food Science and Technology. 102.

https://digitalcommons.unl.edu/foodsciefacpub/102

This Article is brought to you for free and open access by the Food Science and Technology Department at DigitalCommons@University of Nebraska - Lincoln. It has been accepted for inclusion in Faculty Publications in Food Science and Technology by an authorized administrator of DigitalCommons@University of Nebraska - Lincoln. 


\title{
Functionality Behavior of Raw and Extruded Corn Starch Mixtures ${ }^{1}$
}

\author{
Serap Ozcan ${ }^{2}$ and David S. Jackson ${ }^{2.3}$
}

\section{ABSTRACT}

Cereal Chem. 82(2):223-227

Relationships between the structural properties of raw and extruded corn starches and their functionalities were investigated using mixtures of these starch types. Extruded starch had higher water absorption and water solubility indices, and produced lower RVA viscosity profiles when compared with raw starch. It also had no differential scanning calorimetry (DSC) endotherm. Gel cohesiveness and adhesiveness of both starch types were similar, while extruded starch gels were softer. Extruded starch produced lower Rapid Visco Analyser (RVA) viscosity profiles than raw starch due to starch degradation during extrusion. The raw and exfruded starch components bad negative interaction coefficients, thus RVA viscosity parameters were lowered as the fraction of extruded starch in the mixture increased. Starch degradation in the extruded starch was a likely significant factor associated with low viscosity profiles. Mixtures of raw and extruded starches could be commercially prepared to obtain finished starch products with a range of functional attributes.
Extrusion is a process that combines several unit operations such as mixing, cooking, shaping, drying, and expanding (Wiedman and Strobel 1987). Extrusion cooking provides unique physical and chemical functionality to food materials. Extrusion of starch granules causes changes in their morphological and molecular structure depending on several factors including moisture content, cooking temperature, and mechanical/thermal energy input (Donald et al 1993). Extrusion of starch is a physical modification method involving high heat and shear.

When starch is heated in excess water, it gelatinizes. For complete starch gelatinization to occur, at least 14 water molecules per glucose unit are necessary (Donovan 1979; Wang et al 1991). If a stoichiometric conversion is conducted, $61 \%$ water is required to completely gelatinize $39 \%$ starch $(w / w)$. When water is limited $(<35 \%)$, as in many extrusion processes, complete starch cooking involves (at least) two mechanisms: one occurring in the presence of water (gelatinization) and the other occurring at water-limiting conditions (melting) (Wang 1993). Melting and gelatinization require starch conversion from a crystalline to amorphous structure (cooked starch) (Wang 1993). Wang et al (1989) described the conversion of raw starch to cooked starch at low water contents $(<35 \%)$ as a 0th order transition, meaning that the rate of conversion is independent of water content. Under these conditions, most of the starch is melted rather than gelatinized.

Waigh et al $(2000 \mathrm{a}, \mathrm{b})$ described the conversion of raw starch to cooked starch as a single step when moisture contents were $<5 \%$. A direct helix to coil transition occurs as dry starch crystallites melt to form anorphous gels at high temperatures. According to these researchers, when water is added (from $5 \%$ ) up to $40 \%$ (limited water conditions), starch gelatinization proceeds in two steps, first involving an amylopectin helix dislocation and then, second, a helix-coil transition (melting) as amylopectin helices unwind and form amorphous gels.

Shear or mechanical energy input also affects starch cooking (Wang 1993). Extrusion at low temperatures $\left(<50^{\circ} \mathrm{C}\right.$, to prevent starch gelatinization by heating) and low moisture contents $(<35 \%)$ with high shear rates could "cook" up to $65 \%$ of the raw starch. Sauza and Andrade (2002) used DSC to evaluate the melting of corn starch at various water contents. When there was no water present, starch melted at $168^{\circ} \mathrm{C}$; when the water content was $20 \%$, the melting temperature was $123^{\circ} \mathrm{C}$. The DSC melting peak was

\footnotetext{
${ }^{1}$ Contribution of the University of Nebraska Agriculture Research Division, Lincoln, NE 68583. Journal Series No. 14263.

2 Former graduate research assistant and professor, respectively, Department of

Food Science and Technology, University of Nebraska, Lincoln, NE 68583-0919.

${ }^{3}$ Corresponding author. Fax: 402-472-1693. E-mail: djackson@uninotes.unt.edu

DO1: $10.1094 / C C-82-0223$

2005 American Association of Cereal Chemists, Inc.
}

lowered to $73^{\circ} \mathrm{C}$ when $60 \%$ water was present. Starch extruded at low water contents is also frequently degraded due to high shear and heat (Tang and Ding 1994). Starch degradation is necessary for product expansion during extrusion, and optimal expansion for all corn starch types (0-70\% amylose) extruded at different temperatures $\left(130-160^{\circ} \mathrm{C}\right)$ was obtained when its moisture content was 13-14\% (Chinnaswamy and Hanna 1988a,b). Extrusion of starch at a high temperature and a low moisture content with moderate shear resulted in the starch being both gelatinized and melted into a fully cooked amorphous product that crystallizes after being cooled.

Extruded starches can have an improved functionality in food applications, particularly in instantized hot or cold applications. Because starch conversion (gelatinization, melting, and degradation) has a direct influence on final product texture such as expansion, incorporation of an extruded-raw starch mixture might also have a desirable or unique functionality in certain products. For example, tortilla chips require some degraded starch for expansion and some raw starch to support bubbles formed during frying (Lanner et al 2003).

This work was designed to improve our understanding of the functional roles played by extruded and raw starch mixtures in foods. In addition, the feasibility of producing new and predictable functional starch formulations containing raw and extruded starch mixtures was assessed.

\section{MATERIALS AND METHODS}

\section{Materials}

Regular corn starch, obtained from Cargill, Inc. (Cerestar USA, Hammond, IN), was used as a raw material in the preparation of starch mixtures.

\section{Experimental Design and Statistical Analysis}

A mixture augmented-simplex lattice design with two starch components (raw and extruded) was used. A total of eight experiments (Table I) with three replicates were generated using Design Expert statistical software (v. 6.10, Stat-Ease Inc., Minneapolis, $\mathrm{MN}$ ). The points chosen were the pure components, the center point, and check blends (to augment the design). All data collected according to the simplex lattice design were analyzed using Design Expert statistical software.

Because extruded starch does not show any peak on the DSC thermograms, analysis of mixtures with $100 \%$ extruded starch would be considered "missing points," making the design unsuitable. Thus, for DSC data, a user-defined mixture design was used. A total of seven experiments were generated using Design Expert statistical software. Table II lists the actual mixtures created for this experiment. The base model was a Quadratic-Scheffe model. 
The high fraction limit $(0.75)$ for extruded starch (thus the low limit for raw starch in the mixture was 0.25 ) was determined to yield a consistent peak in the DSC (data not shown). All data collected were analyzed using Design Expert statistical software.

Data analyses involved several steps, with the goal being to find the best model (linear or quadratic) to fit the data. First, a significant model was chosen with insignificant lack of fit (LOF) value. Backward elimination was next performed to remove insig. nificant model terms. A reasonable agreement between the predicted $R^{2}$ and adjusted $R^{2}$ values were sought for each analysis. A probability plot of the Studentized residuals was checked for normality of residuals. Studentized residuals versus predicted values were verified for constant error. Outlier $t$ versus run order was investigated for outliers; then outliers were removed if necessary (Stat-Ease 2000). A positive interaction coefficient in a model means that the corresponding terms are synergistic, while a negative interaction coefficient in a model means that the corresponding terms have antagonistic blending effects.

For a given response, to fit the data with a suitable model, $R^{2}$ values should be close to 1 at the selected level of significance ( $P$ $<0.05)$ and lack of fit (LOF) should not be significant $(P>0.05)$ if the chosen model is suitable. An insignificant LOF value means that extra design points, other than the design points used to predict the response, fit the model. Thus, models with high $R^{2}$ values and insignificant LOF values can be used to adequately predict the response within the design space (Comell 1981). A significant LOF value means that model is biased and thus not suitable for prediction.

\section{Preparation of Starch System Components}

Mixtures of raw and extruded starches were prepared according to the specified treatment combinations using Design Expert statistical software (Tables I and II). 1. Raw starch. Raw commercial starch (10.2\% moisture) was used without any treatment. 2. Extruded starch. Native corn starch $(+\approx 20 \%$ water) was extruded in a conical twin-screw extruder (C.W. Brabender model 2802) with a nozzle diameter of $3 \mathrm{~mm}$ and a screw speed of 140 rpm. Feed and rod die/barrel temperatures were $25^{\circ} \mathrm{C}$ and $165^{\circ} \mathrm{C}$, respectively. Extruded starch strands of $\approx 300 \mathrm{~g}$ were collected after steady-state flow was reached in the extruder. The extruded sample (final moisture content of $8.72 \%$ ) was ground using an analytical mill (Tekmar Co., Cincinnati, $\mathrm{OH}$ ) and then stored at room temperature.

\section{Differential Scanning Calorimetry}

Starch endotherms were obtained using a differential scanning calorimeter (Pyris 1, Perkin Elmer Co., Norwalk, CT). Indium was used to calibrate the DSC and a sealed empty pan was used as the reference pan. Freeze-dried treated starch samples $(9-10 \mathrm{mg}$, db) were weighed into stainless steel pans (0319-1525, Perkin-Elmer). Distilled water was added in excess $(80 \%, w / v)$ and pans were hermetically sealed, equilibrated overnight at $20^{\circ} \mathrm{C}$, and heated from 25 to $125^{\circ} \mathrm{C}$ at a $5^{\circ} \mathrm{C} / \mathrm{min}$ heating rate. DSC parameters such as peak, onset, end temperatures, and enthalpies were calculated from the endotherms.

TABLE I

Starch Mixture Ratios Used in the Simplex Lattice Experiment

\begin{tabular}{lccl}
\hline Combination & Raw & Extruded & \multicolumn{1}{c}{ Blends } \\
\hline 1 & 1.00 & 0.00 & Pure blend \\
2 & 1.00 & 0.00 & Pure blend \\
3 & 0.75 & 0.25 & Axial check blend \\
4 & 0.50 & 0.50 & Binary blend (centroid) \\
5 & 0.50 & 0.50 & Binary blend (centroid) \\
6 & 0.25 & 0.75 & Axial check blend \\
7 & 0.00 & 1.00 & Pure blend \\
8 & 0.00 & 1.00 & Pure blend \\
\hline
\end{tabular}

\section{Water Solubility/Absorption Index}

Water solubility/absorption indices (WSI/WAI) were determined as described by Anderson et al (1969). The gel obtained at the bottom of tube was weighed for WAI ( $\mathrm{g}$ of gel/g of dry sample), while the dried supernatant weight was expressed as WSI\% (g of dry solids/g of dry sample).

\section{Viscosity Profiles (RVA) of Starch Mixtures}

Each starch structure type and mixtures $(6 \mathrm{~g}, \mathrm{db})$ were combined with $40 \mathrm{~mL}$ of deionized distilled water in an aluminum cup containing a plastic paddle. Samples were stirred at $160 \mathrm{rpm}$ in a Rapid Visco Analyser (RVA-Series 4, Newport Scientific Pty. Ltd., Warriewood, Australia). Samples were equilibrated at $30^{\circ} \mathrm{C}$ for $10 \mathrm{~min}$, heated to $95^{\circ} \mathrm{C}$ over $6 \mathrm{~min}$, held at $95^{\circ} \mathrm{C}$ for $5 \mathrm{~min}$, cooled to $50^{\circ} \mathrm{C}$ over $4 \mathrm{~min}$, and held for $10 \mathrm{~min}$ at $50^{\circ} \mathrm{C}$. RVA parameters such as peak viscosity, breakdown, final viscosity, and setback were calculated using Thermocline software (v. 2.3, Newport Scientific). The RVA was calibrated as specified by the manufacturer before use.

\section{Gel Textural Attributes of Starch Samples}

After RVA analysis, the resulting pastes were poured into aluminum weighing dishes ( $4 \mathrm{~cm}$ diameter and $1.5 \mathrm{~cm}$ high), cooled to room temperature $\left(20^{\circ} \mathrm{C}\right)$, and subsequently stored at this temperature for $24 \mathrm{hr}$. Gel textural properties were analyzed using a texture analyzer equipped with a $25 \mathrm{~N}$ load cell, (model TA-XT2I. Texture Technologies Corp., New York, NY). An aluminum cylinder probe $(50 \mathrm{~mm})$ with force and distance settings of $5 \mathrm{~N}$ and $3 \mathrm{~mm}$, respectively, was used to compress the gels. Texture Expert texture analysis software (v. 1.5, Stable Micro Systems) was used to calculate hardness, cohesiveness, and adhesiveness as described by Walker et al (1988).

High-Performance Size-Exclusion Chromatography (HPSEC)

Raw and extruded starches were dispersed $(1 \% \mathrm{w} / \mathrm{v})$ using $90 \%$ DMSO and placed in a boiling water bath for $1 \mathrm{hr}$ with frequent vortexing (high setting). Dispersed samples were filtered through a 1.2- $\mu \mathrm{m}$ nylon filter, then injected into an HPSEC system consisting of four KS-series Shodex Ionpak columns (Showa Denko, Tokyo, Japan) connected in series to a refractive index detector (Waters model 410, Millipore Co., Milford, MA). Deionized distilled water $(1 \mathrm{~mL} / \mathrm{min})$ was used as the mobile phase. Astra software (v, 4.70.07, Wyatt Technology Inc, Santa Barbara, CA) was used to measure amylose and amylopectin peaks (Jackson 1991).

\section{RESULTS AND DISCUSSION}

\section{Water Solubility/Absorption Index}

Significant linear models with interaction describing the relationships between raw-extruded starch mixtures and both water solubility index (WSI $R^{2}=0.99, P<0.05, \mathrm{LOF}=0.815$ ) and water absorption index (WAI $R^{2}=0.99, P<0.05, L O F=0.528$ ) were found (Fig. 1A,B). Raw and extruded starches had different WSI and WAI values (Fig. 1A); extruded starch solubility was very high $(24.6 \%)$. During extrusion, starch structures are disrupted and crystalline regions are melted. After this melting

TABLE II

Starch Mixture Ratios Used in the User-Defined Mixture Experiment

\begin{tabular}{lccl}
\hline Combination & Raw & Extruded & \multicolumn{1}{c}{ Blends } \\
\hline 1 & 1.00 & 0.00 & Pure blend \\
2 & 0.81 & 0.19 & Axial check blend \\
3 & 0.75 & 0.25 & Thirds of blends \\
4 & 0.63 & 0.38 & Binary blend (centroid) \\
5 & 0.50 & 0.50 & Thirds of blends \\
6 & 0.44 & 0.56 & Axial check blend \\
7 & 0.25 & 0.75 & Pure blend \\
\hline
\end{tabular}


process, high shear and high temperature conditions result in molecular fragmentation causing increased solubility. Figure 2 compares amylopectin and amylose HPSEC profiles of the raw starch and the extruded starch. The degradation of the amylopectin fraction to a smaller size molecule (amylose-like in size) was observed; this trend is consistent with previously conducted research (Jackson et al 1990). These amylose-like sized molecules are not amylose, as extruded starch had a lower percent amylose content than raw starch because of slight amylose degradation, when measured colorimetrically using iodine binding (data not shown). Water content governs the melting temperature of corn starch, which is $\approx 123^{\circ} \mathrm{C}$ at $20 \%$ moisture as indicated by the DSC peak temperature of the melting endotherm (Sauza and Andrade 2002 ). For our extrusion at $165^{\circ} \mathrm{C}$ (product temperature $\approx 165$ $170^{\circ} \mathrm{C}$ ) with shear, these conditions would be high enough to completely gelatinize and melt the starch. Starch with no granular integrity is in a physically dissociated form or a fragmented form
(Thomas and Atwell 1999). As a result, it is reasonable that our extruded starch would be highly solubilized (dispersed) in water giving a high WSI. The WAI at $30^{\circ} \mathrm{C}$ (Fig. 1B) of extruded starch was also higher than raw starch due to swelling of highly degraded starch (Whalen 1999).

\section{Differential Scanning Calorimetry}

There were no significant models (linear or quadratic) that fit the DSC onset, peak, and end temperatures of the mixtures. The mean values were appropriate predictors of these parameters: DSC onset, peak, and end temperature means, as predicted by the design, were $67.6^{\circ} \mathrm{C}( \pm 0.41), 72.3^{\circ} \mathrm{C}( \pm 0.45)$, and $76.7^{\circ} \mathrm{C}( \pm 0.42)$, respectively. Because starch crystallites are already melted/gelatinized in extruded starch, raw starch was the only component contributing to the DSC onset, peak, and end temperatures. There was no DSC endotherm peak observed for the $100 \%$ extruded starch. Figure 4 shows the DSC thermograms of various raw
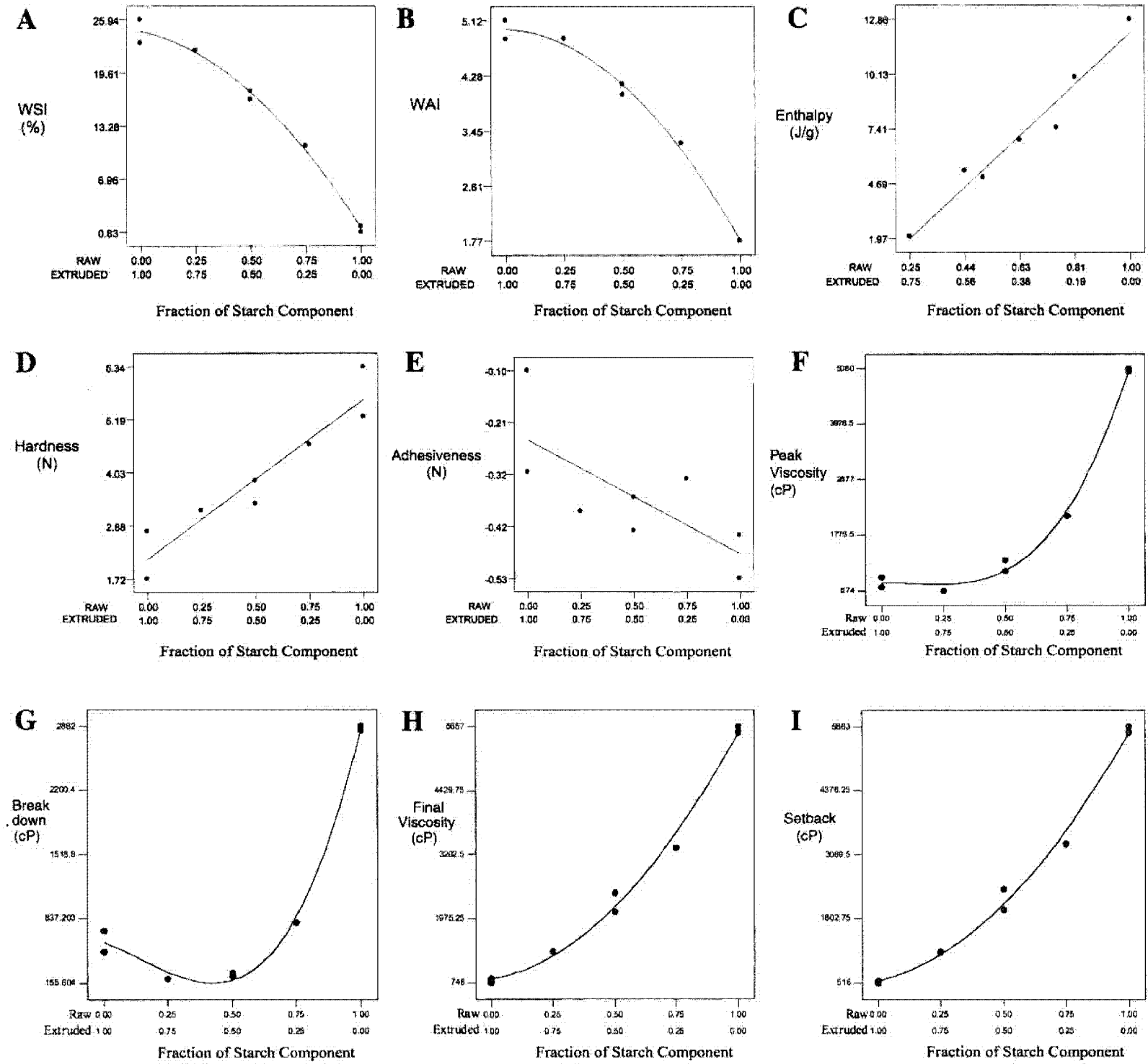

Fig. 1. Two-component mix plots for raw (A) and extruded (B) starch. A, Water solubility index (\%WSI) $=1.06 \mathrm{~A}+24.6 \mathrm{~B}+17.8 \mathrm{AB} . R^{2}>0.99, P<$ 0.05, LOF $=0.815$. B, Water absorption index $(\mathrm{WAI})=1.79 \mathrm{~A}+4.99 \mathrm{~B}+3.03 \mathrm{AB} . R^{2}>0.99, P<0.05, \mathrm{LOF}=0.528 . \mathrm{C}, \mathrm{DSC}$ enthalpy $(\mathrm{J} / \mathrm{g})=12.2 \mathrm{~A}+$ $1.97 \mathrm{~B} . R^{2}=0.96, P<0.05 . \mathrm{D}$, TA hardness $(\mathrm{N})=5.64 \mathrm{~A}+2.15 \mathrm{~B} . R^{2}=0.88, P<0.05, \mathrm{LOF}=0.873$. E, TA adhesiveness $(\mathrm{N})=-0.47 \mathrm{~A}-0.25 \mathrm{~B} . R^{2}=$ $0.55, P<0.05$, LOF $=0.573$. F, RVA peak viscosity $(\mathrm{cP})=5037.9 \mathrm{~A}+828.4 \mathrm{~B}-7428.9 \mathrm{AB}-3358.7 \mathrm{AB} \times(\mathrm{A}-\mathrm{B}) . R^{2}>0.99, P<0.05, \mathrm{LOF}=0.15 . \mathrm{G}$, RVA breakdown $(\mathrm{cP})=2850.6 \mathrm{~A}+587.6 \mathrm{~B}-6134.4 \mathrm{AB}-2872.0 \mathrm{AB} \times(\mathrm{A}-\mathrm{B}) . R^{2}>0.99, P<0.05, \mathrm{LOF}=0.25$. H, RVA final viscosity $(\mathrm{cP})=5538.4 \mathrm{~A}+$ $817.7 \mathrm{~B}-3865.4 \mathrm{AB} . R^{2}=0.99, P<0.05, \mathrm{LOF}=0.23$. I, RVA setback $(\mathrm{cP})=5522.0 \mathrm{~A}+562.0 \mathrm{~B}-3879.8 \mathrm{AB} . R^{2}=0.99, P<0.05, \mathrm{LOF}=0.32$. 
starch/extruded starch mixtures. A linear model (Fig. 1C) was selected for DSC enthalpy $\left(R^{2}=0.96, P<0.05\right)$. Raw starch contributed to enthalpy values; as expected, the more raw starch in the mixture, the higher the mixture's enthalpy.

\section{Gel Textural Attributes}

Texture analysis (TA) parameters such as cohesiveness and adhesiveness were similar for the mixture gels. While raw and extruded starch mixture models provided no additional information other than the mean about gel cohesiveness (mean $=0.69$ $\pm 0.17 \mathrm{~N} / \mathrm{N}$ ), linear models (Fig. ID,E) were fitted to adhesiveness $\left(P<0.05\right.$, LOF $\left.=0.573, R^{2}=0.55\right)$ and hardness $(P<0.05$, LOF $=0.873, R^{2}=0.88$ ). Raw starch yielded harder gels than

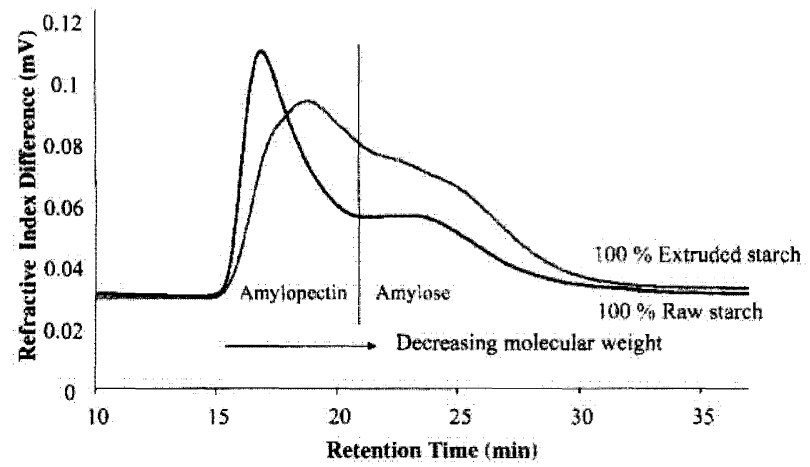

Fig. 2. High-performance size-exclusion chromatography profiles of $100 \%$ extruded and $100 \%$ raw starches. Measured using a refractive index detector with retention time ( $\mathrm{min}$ ) as the $x$-axis and refractive index difference $(\mathrm{mV})$ as the $y$-axis.

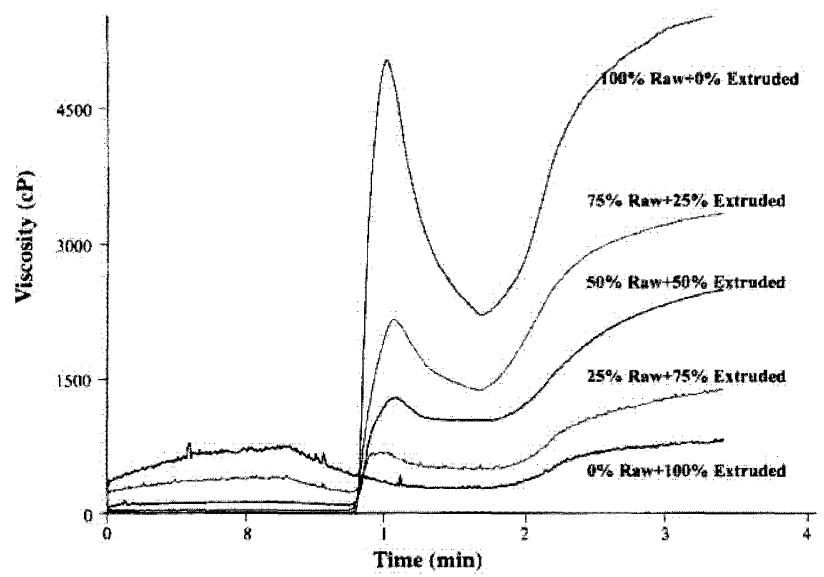

Fig. 3. RVA profiles of raw starch and extruded starch mixtures. extruded starch. Extrusion of starch caused the degradation of amylopectin molecules as seen in HPSEC profiles (Fig. 2), most probably the cleavage of outer linear chains (Chinnaswamy and Hanna 1990; Jackson et al 1990). This cleavage likely results in molecules with clustered short branches that do not easily align with similar polymers. Thus, when the extruded starch was pasted, degraded molecules solubilized quickly and developed an initial cold water viscosity (Fig. 3) but did not form a firm gel upon cooling due to the polymerized polymer chains.

\section{Viscosity Profiles (RVA) of Mixtures}

RVA viscosity parameters of extruded and raw starches were significantly different ( $P<0.05$, Fig. $1 \mathrm{~F}$ and $\mathrm{I}$ and Fig. 3). Extruded starch had significantly decreased RVA viscosity parameters relative to raw starch (Fig. 1F,I). Lower viscosity values observed for extruded starch are influenced by molecular degradation during extrusion. Linear models with interactions were suitable to explain all RVA parameters (Table III) including RVA peak viscosity $\left(\mathrm{P}<0.05\right.$, LOF $=0.15, R^{2}>0.99$ ), RVA breakdown $\left(\mathrm{P}<0.05\right.$, LOF $\left.=0.25, R^{2}>0.99\right)$, RVA final viscosity $\left(P<0.05\right.$, LOF $\left.=0.23, R^{2}=0.99\right)$, and RVA setback $(P<0.05$, LOF $=0.32, R^{2}=0.99$ ). Figure 3 shows RVA profiles of raw and extruded starch mixtures. An initial cold water viscosity was observed for the mixtures containing higher amounts of extruded starch. This cold paste viscosity, confirmed and supported by the extruded starch's WSI and WAI values, was noted by Whalen (1999) to depend on the type and degree of starch degradation. Initial viscosity formation was not observed for $100 \%$ raw starch at low temperatures $\left(30^{\circ} \mathrm{C}\right)$.

There was a negative interaction between raw and extruded starches for all RVA parameter models. RVA peak viscosity and breakdown of mixtures are shown in Fig. 1F,G. When the extruded starch fraction was $<0.50$, peak viscosity, and breakdown values increased rapidly, suggesting that extruded starch strongly affects the viscosity behavior of the mixture until raw starch completely gelatinizes. RVA final viscosity and setback increase quickly when the extruded starch fraction was $<0.75$

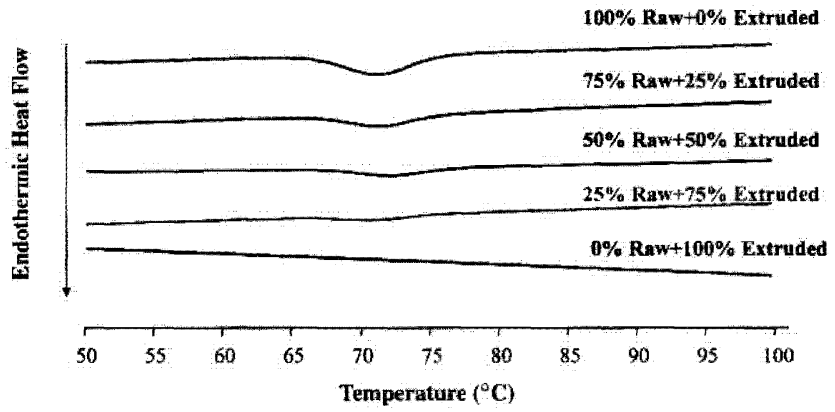

Fig. 4. DSC thermograms of raw starch and extruded starch mixtures.

TABLE III

Summary of Model Equations for Each Response (A = raw starch, B = extruded starch)

\begin{tabular}{|c|c|c|c|}
\hline Response & Equations & $\boldsymbol{R}^{2}$ & Model \\
\hline WSI\% & $1.06 \mathrm{~A}+24.6 \mathrm{~B}+17.8 \mathrm{AB}$ & $>0.99$ & Linear with interaction \\
\hline WAI & $1.79 \mathrm{~A}+4.99 \mathrm{~B}+3.03 \mathrm{AB}$ & $>0.99$ & Linear with interaction \\
\hline DSC Onset temperature & $=$ Mean is the better predictor. There is no significant model to fit. Mean $=67.6$ & $\cdots$ & $\cdots$ \\
\hline DSC Peak temperature & Mean is the better predictor. There is no significant model to fit. Mean $=72.3$ & $\ldots$ & $\cdots$ \\
\hline DSC Enthalpy & $=12.2 \mathrm{~A}+1.97 \mathrm{~B}$ & 0.96 & Linear \\
\hline DSC End temperature & $=$ Mean is the better predictor. There is no significant model to fit. Mean $=76.7$ & $\cdots$ & $\cdots$ \\
\hline TA Cohesiveness & $=$ Mean is the better predictor. There is no significant model to fit. Mean $=0.69$ & $\cdots$ & $\cdots$ \\
\hline TA Hardness & $=5.64 \mathrm{~A}+2.15 \mathrm{~B}$ & 0.88 & Linear \\
\hline TA Adhesiveness & $=-0.47 \mathrm{~A}-0.25 \mathrm{~B}$ & 0.55 & Linear \\
\hline RVA Peak viscosity & $=5037.9 \mathrm{~A}+828.4 \mathrm{~B}-7428.9 \mathrm{AB}-3358.7 \mathrm{AB} \times(\mathrm{A}-\mathrm{B})$ & $>0.99$ & Linear with interaction \\
\hline RVA Breakdown & $=2850.6 \mathrm{~A}+587.6 \mathrm{~B}-6134.4 \mathrm{AB}-2872.0 \mathrm{AB} \times(\mathrm{A}-\mathrm{B})$ & $>0.99$ & Linear with interaction \\
\hline RVA Final viscosity & $=5538.4 \mathrm{~A}+817.7 \mathrm{~B}-3865.4 \mathrm{AB}$ & 0.99 & Linear with interaction \\
\hline RVA Setback & $=5522.0 \mathrm{~A}+560.2 \mathrm{~B}-3833.3 \mathrm{AB}$ & 0.99 & Linear with interaction \\
\hline
\end{tabular}


(Fig. 1H and I), suggesting that raw starch is responsible for the viscosity development upon cooling. When extruded starch is mixed with raw starch, the extruded starch fragments might be quickly dispersed in the water covering the exterior of the raw starch granules or clogging the pores on the surface of raw starch granules. Additionally, extruded starch fragments might reassociate with the uncoiled amylopectin branches (Chinnaswamy et al 1989), partially limiting water absorption (Donald et al 2001).

\section{CONCLUSIONS}

Water solubility and absorption of extruded starch was higher than for raw starch due to molecular fragmentation during the high shear and high temperature extrusion conditions and due to swelling of highly degraded starch, respectively. There was no DSC endotherm peak observed for the 100\% extruded starch. Raw starch was the only component affecting DSC onset, peak, and end temperatures. The contributions of raw and extruded starch mixtures to enthalpy values could be predicted based on a linear model. As the raw starch fraction increased in the mixture, mixture enthalpy increased and as the extruded starch fraction increased up to $75 \%$, mixture enthalpy decreased to as low as $1.97 \mathrm{~J} / \mathrm{g}$. Raw starch made harder gels than extruded starch. Although an initial RVA cold water viscosity was observed for the extruded starch, the extruded starch interacted with the raw starch decreasing other viscosity profiles values.

Mixtures of raw and extruded starches can contribute different functionalities to food systems; the resulting functionalities are not always linear responses easily predicted by examining the component's individual functional behaviors. These models can aid in developing or improving products with desired functionalities. For example, mixtures of raw and extruded starches could be commercially prepared to provide new starch ingredients with predictable functional behaviors. Processing with these starch mixtures (for example, re-extrusion, frying, or baking) is worth additional investigation so that further strides can be made toward eventually understanding the roles these starch structures have in imparting functional characteristics to foods.

\section{LITERATURE CITED}

Anderson, R. A., Conway, H. F., Pfeifer, V. F., and Griffin, E. L. 1969. Gelatinization of corn grits by roll and extrusion cooking. Cereal Sci. Today 14:4-7.

Chinnaswamy, R., and Hanna, M. A. 1988a. Optimum extrusion cooking condition for maximum expansion of com starch. J. Food Sci. 63:834840 .

Chinnaswamy, R., and Hanna, M. A. 1988b. Relation between amylose content and extrusion-expansion properties of com starches. Cereal Chem. 65:138-143.
Chinnaswamy, R., and Hanna. M. A. 1990. Macromolecular and functional properties of native and extrusion-cooked corn starch. Cereal Chem. 67:490-499.

Chinnaswamy, R., Hanna, M. A., and Zobel, H. F. 1989. Microstructural, physiochemical, and macromolecular changes in extrusion-cooked and retrograded corn starch. Cereal Foods World 34:415.

Cornell, J. A. 1981. Experiments With Mixtures: Designs, Models and the Analysis of Mixture Data. John Wiley and Sons: New York.

Donald. A. M., Smith. A. C. and Warburton, S. C. 1993. Physical changes consequent upon extrusion of the starch. Pages 375 in: The Glassy State In Foods. J. M. V. Blanshard and P. J. Lillford, eds. Nottingham University Press: Nottingham, UK.

Donovan, J. W. 1979. Phase transition of the starch-water system. Biopolymers 18:263-267.

Jackson, D. S. 1991. Solubility behavior of granular corn starches in methyl sulfoxide (DMSO) as measured by high performance size exclusion chromatography. Starch 43:422-427.

Jackson, D. S., Gomez, M. H., Waniska, R. D., and Rooney, L. W. 1990. Effects of single-screw extrusion cooking on starch as measured by aqueous high performance size exclusion chromatography. Cereal Chem. 67:529-532.

Lanner, D. A., Hsieh, Y.-P. C., Zimmerman, S. P., Teras, L. M., Jones, C. E. Herring, J. R., Groves, R. W., and Fiteny, M. J. 2003. Process for making tortilla chips with controlled surface bubbling. US patent $6,572,910$.

Sauza, R. C. R. and Andrade, C. T. 2002. Investigation of the gelatinization and extrusion processes of com starch. Adv. Polym. Technol. 21:17-24.

Tang, J., and Ding, X. 1994. Relationship between functional properties and macromolecular modifications of extruded corn starch. Cereal Chem. 71:364-369.

Thomas, D. J., and Atwell, W. A. 1999. Starches. AACC: St. Paul, MN.

Waigh, T. A., Kato, K. L., Donald, A. M., Gidley, M. J., Clarke, C. J., and Riekel, C. 2000a. Side-chain liquid-crystalline model for starch. Starch $52: 450-460$.

Waigh, T. A, Gidley, M. J., Komanshek, B. U., and Donald, A. M. 2000 b. The phase transformations in starch during gelatinization: $A$ liquid crystalline approach. Carbohydr. Res. 328:165-176.

Walker, C. E., Ross, A. S., Wrigley, C. W., and McMaster, G. J. 1988. Accelerated starch paste characterization with the rapid viscoanalyzer. Cereal Foods World 33:491.

Wang, S. S. 1993. Gelatinization and melting of starch and tribochemistry in extrusion. Starch 45:388-390.

Wang. S. S., Chiang, W. C., Yeh, A. L., Zhao, B., and Kim, I. H. 1989. Kinetics of phase transition of waxy com starch at extrusion temperatures and moisture contents. J. Food Sci. 54: 1298-1301.

Wang, S. S., Chiang, W. C.. Zhao, B., Zheng, X., and Kim, I. H. 1991. Experimental analysis and computer simulation of starch-water interactions during phase transition. J. Food Sci. 56:121-124.

Whalen, P. J. 1999. Measuring process effects in ready-to-eat breakfast cereals. Cereal Foods World 44:407-412.

Wiedman, W., and Strobel, E. 1987. Processing and economic advantages of extrusion cooking in comparison with conventional processing in the food industry. Pages 132-169 in: Extrusion Technology for the Food Industry. C. O'Connor, ed. ElsevierApplied Science: New York.

[Received June 14, 2004. Accepted October 8, 2004.$]$ 